\title{
A INTELIGÊNCIA COMPETITIVA E O DESENVOLVIMENTO DE CAPACIDADES DINÂMICAS NAS ORGANIZAÇÕES
}

\section{RESUMO}

Este trabalho tem dois objetivos. O primeiro é estudar os conceitos de Inteligência Competitiva e de Capacidades Dinâmicas, buscando identificar se as etapas do ciclo de inteligência competitiva podem se constituir em elementos mobilizadores de Capacidades Dinâmicas nas organizações. O segundo é identificar como se encontra o processo de inteligência competitiva nas empresas brasileiras de médio e grande porte, tendo como base a opinião de especialistas sobre o tema (acadêmicos, pesquisadores e consultores). Para a sua consecução, além da revisão de literatura, coletaram-se dados mediante a realização de entrevistas em profundidade e, visando a triangulação de informações, realizaram-se buscas em estudos de natureza semelhante. Trata-se de uma pesquisa qualitativa que empregou como técnica de exame dos dados a análise de conteúdo. Defende-se que as rotinas das etapas do ciclo de inteligência competitiva e as habilidades requeridas para a sua operacionalização, favorecem a mobilização de Capacidades Dinâmicas nas organizações. A Inteligência Competitiva, mediante o adequado desenvolvimento das atividades estabelecidas em suas fases, age no sentido de favorecer a percepção da mudança (sensing) e de fornecer a inteligência necessária à apropriação do conhecimento que servirá de base para a ação (seizing), contribuindo, assim, para a renovação continuada do negócio (transforming). Por outro lado, as evidências sugerem que as práticas de Inteligência Competitiva ainda estão em estágio inicial de aplicação nas empresas brasileiras, necessitando, assim, de esforços para a sua qualificação e consolidação.

Palavras-chave: Inteligência Competitiva; Capacidades Dinâmicas; Estratégia Empresarial.

\section{THE COMPETITIVE INTELLIGENCE AND THE DEVELOPMENT OF DYNAMIC CAPABILITIES IN ORGANIZATIONS}

\begin{abstract}
This article has two objectives. The first is to study the concepts of Competitive Intelligence and Dynamic Capabilities, aiming to verify if the stages of the competitive intelligence cycle can constitute stimulating elements for Dynamic Capabilities in organizations. The second goal is to understand how the competitive intelligence process is dealt with in medium- and large-sized companies in Brazil, grounded on opinions by specialists on the topic (scholars, researchers and consultants). For its consecution, besides the literature review on the subject, information was collected by means of in-depth interviews and, seeking triangulation of data, a comparative research was conducted on similar studies. It is a qualitative research that applies content analysis as its technique for investigation. The study supports that the routines in the stages of the competitive intelligence cycle and the abilities required for its operationalization foster the mobilization of Dynamic Capabilities in organizations. Competitive Intelligence, through a suitable development of the activities established in its phases, promotes the perception for change (sensing) and provides the necessary intelligence for the acquiring of the knowledge which will be the foundation for action (seizing), thus contributing for the continuous reinvention of the business (transforming). On the other hand, evidences suggest that Competitive Intelligence practices are still in their embryonic stages of application in Brazilian companies, and therefore need efforts for further qualification and consolidation.
\end{abstract}

Keywords: Competitive Intelligence; Dynamic Capabilities; Company Strategy. 


\section{A COMPETITIVAS CAPACIDADES DE INTELIGENCIA Y LA DINÁMICA DE DESARROLLO DE LAS} ORGANIZACIONES

\section{RESUMEN}

Este trabajo tiene dos objetivos. La primera es el estudio de los conceptos de Inteligencia Competitiva y capacidades dinámicas a fin de identificar las etapas del ciclo de inteligencia competitiva puede ser en la movilización de elementos de las capacidades dinámicas en las organizaciones. El segundo es identificar cómo es el proceso de inteligencia competitiva en las empresas brasileñas de mediano y grande, con base en la opinión de expertos en el tema (académicos, investigadores y consultores). Para su realización, además de la revisión de la literatura, los datos fueron recolectados a través de entrevistas y con el objetivo de triangulación de información, había búsquedas en estudios similares. Se trata de un estudio cualitativo que se emplea como examen de análisis de contenido de datos técnicos. Se argumenta que las rutinas de las etapas del ciclo de inteligencia competitiva y las habilidades necesarias para su aplicación, promover la movilización de las capacidades dinámicas en las organizaciones. La Inteligencia Competitiva por las actividades de desarrollo correspondientes establecidos de fases, actúa para promover la percepción del cambio (detección) y proporcionar la inteligencia necesaria la apropiación del conocimiento como base para la acción (incautación), contribuyendo por lo que para la renovación continua de los negocios (transformación). Por otro lado, la evidencia sugiere que las prácticas de inteligencia competitiva se encuentran todavía en las primeras etapas de la inversión en las empresas brasileñas, por lo que requiere esfuerzos a su calificación y consolidación.

Palabras clave: Inteligencia Competitiva; Las capacidades dinámicas; Estrategia de Negocios.

\footnotetext{
${ }^{1}$ Doutor em Administração pela Universidade do Vale do Rio dos Sinos - UNISINOS. Professor da Escola Superior de Propaganda e Marketing - ESPM. Brasil. E-mail: escalona@cpovo.net
} 


\section{INTRODUÇÃO}

A questão de como o valor é gerado e capturado sempre foi considerada elemento central em estratégia empresarial. Empresas de ponta organizamse, dentro de suas respectivas áreas, para capturar a maior parcela possível da riqueza gerada em seus setores de atuação (Porter, 2008; Magretta, 2012; Porter \& Heppelmann, 2014). Entretanto, a evolução tecnológica, notadamente das tecnologias da informação e da comunicação, tem agido no sentido de alterar estruturas setoriais e seus respectivos padrões dominantes, quanto à forma de geração e captação de riqueza (Porter \& Heppelmann, 2015). A agregação de inteligência e conectividade a produtos tradicionais (Porter \& Heppelmann, 2014; Rifkin, 2014) e o surgimento de tecnologias que permitem a vinculação direta entre oferta e demanda, entre propriedade e necessidade, sem a ação de agentes intermediários, têm favorecido o desenvolvimento de novos modelos de negócios. Esses novos modelos estão transformando a competição, excluindo empresas tradicionais do mercado e criando gigantes corporativos como Uber, Tesla e Airbnb, para citar apenas alguns (Colvin, 2015).

Manterem-se competitivas é um desafio para as empresas já estabelecidas. Para tanto, tem se observado que as mesmas precisam estabelecer processos organizacionais que lhes permitam capturar dados, gerar informação, transformar a informação em inteligência e desenvolver ações táticas e estratégicas que permitam a conquista de vantagem competitiva diante dos concorrentes (Calof \& Wright, 2008; Sharp, 2009; Jin \& Bouthillier, 2013; Ioia, 2014). Também ganha força o argumento de que o desenvolvimento de capacidades e processos organizacionais que visem a adaptar a base de recursos das empresas às novas realidades do ambiente de negócios é elemento indispensável à sua lucratividade e sustentabilidade no longo prazo (Teece, Pisano \& Shuen, 1997; Eisenhardt \& Martin, 2000; Harreld; O'Reilly III \& Tushman, 2007; Teece, 2012). Esses argumentos são identificados na literatura organizacional, respectivamente, sob os títulos de Inteligência Competitiva (IC) e Capacidades Dinâmicas (CDs).

$\mathrm{O}$ conceito de Inteligência Competitiva (IC) tem sido reportado como o processo pelo qual as organizações buscam informações, internas e externas, sobre clientes, fornecedores, concorrentes e o ambiente de negócios, tendo como objetivo transformar tais informações em conhecimento, de tal forma que os gestores possam tomar decisões corretas, já na primeira vez (Kahaner, 1997; Calof \& Wright, 2008). Como observado por Jin e Bouthillier (2013), a essência da IC é lidar com o ambiente competitivo e obter uma perspectiva profunda e acurada sobre o mesmo.

Já a teoria sobre CDs tem evoluído sob o argumento de que mais importante do que encontrar o correto posicionamento diante das forças setoriais, como defendido por Porter, (1980, 2008) e possuir recursos raros, valiosos e difíceis de imitar e substituir, como proposto por Barney (1991), é desenvolver processos e capacidades organizacionais que permitam a renovação continuada de tais recursos, de tal forma que os mesmos sempre estejam atualizados o suficiente para atender as mudanças do ambiente de negócios como um todo (Eisenhardt \& Martin, 2000; Ambrosini \& Bowmann, 2009).

Entretanto, apesar da atualidade do tema CDs e do crescente interesse dos pesquisadores sobre o mesmo (Wang \& Ahmed, 2007), alguns elementos centrais para o desenvolvimento da referida teoria permanecem sem resposta satisfatória. Desconhece-se, por exemplo, como as CDs efetivamente operam no desenvolvimento dos processos e das capacidades organizacionais, notadamente no caso daquelas capacidades que habilitam as organizações a competirem em ambientes cada vez mais dinâmicos (Alsos, Borch, Ljunggren \& Madsen, 2008). Como reportado por Wang e Ahmed (2007), a revisão de alguns conceitos relacionados às CDs, notadamente no sentido de favorecer a sua implementação prática nas organizações, é uma necessidade.

Visando contribuir com tais lacunas, duas questões nortearam o desenvolvimento do presente estudo: i) As etapas do ciclo de inteligência competitiva podem se constituir em elementos mobilizadores de capacidades dinâmicas nas organizações e favorecer o desenvolvimento de processos e habilidades capazes de contribuir para a sua renovação e sustentabilidade no longo prazo? ii) Como se encontra o processo de inteligência competitiva nas organizações brasileiras de médio e grande porte, segundo a opinião de especialistas sobre o tema?

Desta forma, destacam-se como objetivos do presente trabalho: i) estudar os conceitos de inteligência competitiva e capacidades dinâmicas, buscando identificar se as etapas do ciclo de inteligência competitiva podem se constituir em elementos mobilizadores de capacidades dinâmicas nas organizações e, ii) identificar como se encontra o processo de inteligência competitiva nas organizações brasileiras de médio e grande porte, tendo como base a opinião de especialistas sobre o tema.

Para atender os objetivos propostos, realizouse a revisão de literatura sobre os referidos temas e procedeu-se à realização de entrevistas com especialistas em IC. Para realizar a triangulação de dados, desenvolveu-se, também, a busca de estudos similares sobre a realidade das práticas de IC no ambiente brasileiro de negócios.

Ao examinar as etapas do ciclo de inteligência competitiva e sugerir que as mesmas incentivam o desenvolvimento de capacidades, o presente estudo contribui para o desenvolvimento da teoria sobre capacidades dinâmicas, destacando processos organizacionais que favorecem a renovação do 
A Inteligência Competitiva e o Desenvolvimento de Capacidades Dinâmicas nas Organizações

negócio. Adicionalmente, ao apresentar a visão de especialistas sobre $\mathrm{o}$ atual estágio das práticas de inteligência competitiva, adotadas por organizações brasileiras de médio e grande porte, falhas são identificadas. A necessidade de dar destino mais estratégico às práticas de IC, tendo em vista que as mesmas estão muito voltadas para busca de soluções de curto prazo, e de desenvolver redes de inteligência, são exemplos de recomendações apresentadas.

No presente estudo, argumenta-se que a renovação da base de recursos e competências de uma empresa, mediante o desenvolvimento de capacidades e o estabelecimento de processos organizacionais para tanto (CDs), só se torna possível após a adequada leitura da dinâmica competitiva do setor a que a organização pertence. Para agir de maneira correta, ajustada à mudança, a empresa precisa, antes, perceber a mudança. Assim, torna-se indispensável a definição de processos que possibilitem buscar a informação adequada, no tempo certo, e transformar essa informação em inteligência, tendo como objetivo favorecer o ajustamento competitivo da organização.

\section{INTELIGÊNCIA COMPETITIVA}

Informação e inteligência têm conceitos diferentes. Informação é algo objetivo, concreto. São números, estatísticas, são dados dispersos sobre pessoas e empresas e sobre o que eles têm feito. Inteligência, por outro lado, é uma coleção de peças de informação que foi filtrada, destilada e analisada. É algo que lhe permite agir. É o que os gestores precisam para agir. Uma outra palavra para inteligência é conhecimento (Kahaner, 1997).

Em ambientes de negócio onde a informação está cada vez mais acessível a todos os competidores, a mesma deixa de ser um instrumento de possíveis ganhos competitivos. A vantagem competitiva, nessa situação, será decorrente da capacidade de analisar, interpretar, gerar inteligência e promover a aplicação desse conhecimento em benefício do negócio, de forma melhor e mais dinâmica que os demais competidores. Em tais ambientes, a atividade de Inteligência Competitiva (IC) ganha relevância.

Inteligência Competitiva (IC) pode ser definida como o processo pelo qual, de forma organizada e sistemática, as empresas garimpam, analisam e transformam informações sobre mercados, competidores e o ambiente de negócios em geral, em inteligência acionável, de forma a favorecer a conquista de seus objetivos, sejam eles táticos ou estratégicos (Kahaner, 1997).

De acordo com a Strategic and Competitive Intelligence Professionals (SCIP), uma associação global de profissionais que atuam no campo da estratégia e da inteligência competitiva, fundada em 1986, a IC é um processo contínuo que envolve o garimpo de dados brutos, a combinação/harmonização desses dados para criar informação e a análise da informação, visando gerar inteligência acionável para os tomadores de decisão.

Gilad (1989) entende que não é toda a empresa que, de fato, necessita de uma unidade formal de IC. O aumento da competição tem criado essa necessidade, mas é preciso considerar as variáveis que a definem: o tamanho da empresa, o escopo mercadológico, a intensidade da competição no setor e a complexidade da estrutura organizacional. Já Kahaner (1997) defende a existência de um departamento formal de IC capitaneado por um coordenador. Para o referido autor, um programa efetivo de IC requer a existência de um ambiente físico formal.

Para Prescott (1999), o uso da IC dentro das organizações tem contribuído para o compartilhamento de ideias, o acesso a dinâmicas competitivas, a identificação de novas oportunidades e para evitar surpresas. A presença da IC como atividade formal em uma empresa é considerada essencial pelo referido autor, uma vez que as organizações precisam estar atentas aos movimentos dos competidores. $\mathrm{O}$ autor alerta, entretanto, que a IC não é um processo que acontece em passo único, mas algo que é desenvolvido de forma continuada, ao longo de um período de tempo.

Para se manterem competitivas e saberem como se antecipar e reagir às mudanças que ocorrem dentro e fora de seus setores, as empresas precisam estabelecer processos que permitam capturar dados e transformá-los em inteligência acionável, da qual derivarão decisões táticas e, principalmente, estratégicas. O processo de coleta, análise, transformação de dados e informações em inteligência, difusão e uso do conhecimento decorrente denomina-se IC (Leavitt, Prescott, Lemons \& Hasanali, 2004).

Calof e Wright (2008) definem IC como a busca de informações internas e externas sobre competidores, clientes, fornecedores, tecnologias e outros negócios em potencial. A finalidade da IC seria proporcionar alertas antecipados que permitissem prever movimentos competitivos de concorrentes e mudanças no comportamento de clientes, bem como conhecer antecipadamente decisões dos governantes, que possam ter impacto significativo sobre o desempenho e o futuro do negócio.

Para Sharp (2009), a IC tem sido equivocadamente vinculada à análise de competidores. Essa vinculação estreita acaba por limitar o escopo e os benefícios da atividade. Para a referida autora, aqueles que compreendem que a IC envolve muito mais do que apenas monitoramento de competidores podem obter diferenciais competitivos. A IC, para Sharp (2009), diz respeito a ter conhecimento e capacidade de fazer previsões sobre o ambiente de negócios de forma ampla e, ainda, a colocar em ação tais elementos (conhecimento e capacidade de previsão). Para a referida autora, o novo cria oportunidades, pelo menos para aqueles executivos que reconhecem que o novo, quando aplicado aos negócios, é um sinônimo para 
mudança, e é na mudança que oportunidades são encontradas.

Para Jin e Bouthillier (2013), IC é definida como um processo pelo qual uma organização legal e sistematicamente coleta, armazena, mantém, analisa e dissemina informação sobre seu ambiente competitivo tendo como objetivo obter insights sobre tendências de negócios, com vistas à vantagem competitiva. Para os referidos autores, a essência da IC é lidar com o ambiente competitivo e obter uma perspectiva profunda e acurada sobre este, com base no uso de informação.

IC diz respeito à capacidade organizacional de analisar consumidores, mercados e informações competitivas em um processo contínuo, com foco na geração de insights, destinados a ajudar as pessoas de negócio a tomar decisões acerca de eventos futuros. Decisões amparadas por informações coletadas e analisadas pela área de IC tendem a proporcionar vantagem competitiva sustentável para as organizações (Ioia, 2014).

Para Kahaner (1997), a unidade básica de um sistema de inteligência é o ciclo de inteligência. O ciclo de inteligência é o processo pelo qual a informação bruta é transformada em inteligência. Para o referido autor, o processo utilizado por empresas assemelha-se ao que é empregado pela agência de inteligência americana (Central Intelligence Agency - CIA). Esse processo tem quatro passos: planejamento e direção, coleta, análise e disseminação.
Na fase de planejamento e direção, evidenciase o momento em que são definidos o produto desejado e o curso de ação que será tomado na busca de informações. Esta fase é o início e o fim do processo, porque, uma vez que informações sejam entregues e ações sejam implementadas, novas informações e novo planejamento de coleta serão necessários.

A fase de coleta envolve garimpar, buscar informações. Reporta-se à busca de matéria prima bruta para transformá-la em informação. Para Kahaner (1997), a fase de coleta envolve também o processamento e o armazenamento da informação.

A análise é considerada a fase mais difícil do ciclo de IC. Exige habilidade, porque requer que o analista considere as informações, busque por padrões e desenvolva cenários baseado no que ele viu (Kahaner, 1997).

Por sua vez, a disseminação é o último e o primeiro passo do processo. Diz respeito a distribuir/entregar o produto da inteligência àquele que o solicitou. É o momento em que o analista deverá sugerir possíveis cursos de ação. Para tanto, ele deverá ser hábil para logicamente articular e defender seus argumentos (Kahaner, 1997).

Outros renomados autores da área de IC também se reportam ao ciclo de inteligência como sendo a unidade básica de um sistema de inteligência organizacional. O Quadro 1 apresenta a visão de diferentes autores sobre o referido ciclo. 
A Inteligência Competitiva e o Desenvolvimento de Capacidades Dinâmicas nas Organizações

\begin{tabular}{|c|c|c|c|c|c|c|c|}
\hline \multirow{2}{*}{$\begin{array}{l}\text { AUTORES } \\
\text { Fuld (2007). }\end{array}$} & \multicolumn{7}{|c|}{ ETAPAS } \\
\hline & $\begin{array}{l}\text { Planejamento } \\
\text { e direção }\end{array}$ & $\begin{array}{c}\text { Coleta de } \\
\text { informações } \\
\text { secundárias }\end{array}$ & $\begin{array}{c}\text { Coleta de } \\
\text { informações } \\
\text { primárias }\end{array}$ & $\begin{array}{l}\text { Análise e } \\
\text { produção }\end{array}$ & $\begin{array}{l}\text { Reporte e } \\
\text { informação }\end{array}$ & & \\
\hline $\begin{array}{c}\text { Kahaner } \\
(1997)\end{array}$ & $\begin{array}{c}\text { Planejamento } \\
\text { e direção }\end{array}$ & $\begin{array}{c}\text { Coleta de } \\
\text { informações }\end{array}$ & Análise & Disseminação & & & \\
\hline Miller (2002) & $\begin{array}{c}\text { Identificação } \\
\text { necessidades } \\
\text { de } \\
\text { informação }\end{array}$ & $\begin{array}{c}\text { Coleta de } \\
\text { informações }\end{array}$ & Análise & Disseminação & & & \\
\hline Pirtila (1998) & $\begin{array}{c}\text { Definição de } \\
\text { competidores } \\
\text { e } \\
\text { necessidades } \\
\text { de } \\
\text { informação } \\
\end{array}$ & $\begin{array}{c}\text { Coleta } \\
\text { sistemática de } \\
\text { informações }\end{array}$ & $\begin{array}{c}\text { Filtragem e } \\
\text { análise das } \\
\text { informações } \\
\text { coletadas }\end{array}$ & Disseminação & & & \\
\hline $\begin{array}{c}\text { Choo (2002) } \\
- \\
\text { Information } \\
\text { Management } \\
\text { Cycle } \\
\end{array}$ & $\begin{array}{c}\text { Identificação } \\
\text { necessidades } \\
\text { de } \\
\text { informação }\end{array}$ & $\begin{array}{l}\text { Aquisição de } \\
\text { informações }\end{array}$ & $\begin{array}{c}\text { Organização e } \\
\text { armazenamento }\end{array}$ & $\begin{array}{l}\text { Produtos da } \\
\text { informação }\end{array}$ & $\begin{array}{c}\text { Distribuição } \\
\text { da informação }\end{array}$ & $\begin{array}{c}\text { Uso da } \\
\text { Informação }\end{array}$ & \\
\hline $\begin{array}{l}\text { Herring } \\
(2002)\end{array}$ & $\begin{array}{c}\text { Avaliação das } \\
\text { necessidades }\end{array}$ & Planejamento & $\begin{array}{c}\text { Coleta de } \\
\text { informações }\end{array}$ & Análise & Apresentação & & \\
\hline Sharp (2009) & $\begin{array}{l}\text { Coleta de } \\
\text { dados }\end{array}$ & $\begin{array}{l}\text { Transformação } \\
\text { dos dados em } \\
\text { informação }\end{array}$ & $\begin{array}{c}\text { Análise e } \\
\text { produção de } \\
\text { inteligência }\end{array}$ & $\begin{array}{l}\text { Tomada de } \\
\text { decisão }\end{array}$ & Ação & $\begin{array}{l}\text { Análise de } \\
\text { resultados }\end{array}$ & $\begin{array}{c}\text { Nova } \\
\text { coleta } \\
\text { de } \\
\text { dados }\end{array}$ \\
\hline Ioia (2014) & $\begin{array}{l}\text { Planejamento } \\
\text { e direção }\end{array}$ & Coleta & $\begin{array}{l}\text { Processamento } \\
\text { e } \\
\text { armazenamento }\end{array}$ & $\begin{array}{l}\text { Análise e } \\
\text { produção de } \\
\text { inteligência }\end{array}$ & $\begin{array}{l}\text { Disseminação } \\
\text { e avaliação }\end{array}$ & & \\
\hline
\end{tabular}

Quadro 1 - Etapas do ciclo de IC

Fonte: indicadas no quadro

O constante monitoramento do ambiente de negócios permite aos gestores ter conhecimento atualizado sobre as tendências de mercado e promover ações, visando adaptar-se às mudanças de forma mais rápida do que realizariam, se fizessem um escâner do mercado apenas ocasionalmente, ou de modo não tão frequente (Qiu, 2008). Em um mundo de mudanças imprevisíveis, onde os ciclos de negócios estão se tornando cada vez mais curtos, é imperativo que os gestores realizem o monitoramento constante do ambiente de negócios, com uma visão de 360 graus, e que estejam alertas para oportunidades e ameaças (Ioia, 2014).

Laackman, Saban e Lanasa (2000) consideram que a localização na estrutura organizacional do setor de IC é um elemento relevante, pois impactará nas relações dentro da empresa, evidenciará a importância atribuída à atividade e refletirá nas demandas e nos orçamentos destinados a esta. Para os autores, quanto mais alto o posicionamento da IC na hierarquia organizacional, melhor será, pois mais reconhecida e estratégica tende a ser a atividade.

A atividade de IC é exercida de forma diferente em distintas organizações, dependendo da estrutura oferecida à área, das pessoas envolvidas com a atividade, dos sistemas de informação disponibilizados e da cultura da organização. A alocação da área de IC no organograma organizacional é reflexo da importância atribuída a esta pela alta gestão. A vinculação da área às atividades de estratégia e planejamento estratégico e o reporte direto ao Chief Executive Officer (CEO) evidenciam o uso da IC de modo mais estratégico. Por sua vez, a alocação a áreas como desenvolvimento de produtos, vendas, comunicação e marketing evidencia o uso mais tático da IC (Ioia, 2014).

Três grandes elementos interferem decisivamente no exercício das atividades da área de IC: a) a natureza do setor do qual a organização faz parte (se é mais ou menos dinâmico); b) a importância atribuída à atividade pela alta gestão da organização (a estrutura disponibilizada, a cultura relacionada à valorização, à difusão e ao incentivo ao compartilhamento de informações); c) as capacidades do profissional que atua na área (sua experiência, conhecimento, habilidades, relacionamentos, etc.) (Jin \& Bouthillier, 2013). 


\section{CAPACIDADES DINÂMICAS (CDs)}

A capacidade das organizações em integrar, construir e reconfigurar competências internas e externas, visando a seu ajustamento às novas realidades do ambiente competitivo, foi denominada de Capacidades Dinâmicas (CDs) por Teece et al., (1997). Essa investigação teórica originou-se da necessidade de suprir lacunas existentes em outros proeminentes modelos, como, por exemplo, o modelo da análise estrutural de setores (Porter, 1980), tido como limitado por basear sua análise no estudo das cinco forças setoriais e considerar a indústria (setor) de forma isolada, sem computar o amplo ecossistema envolvido no ambiente de negócios (Teece, 2007) e a perspectiva da Visão da Empresa Baseada em Recursos - RBV (Wernerfelt, 1984; Barney, 1991), considerada como limitada na tentativa de explicar como as empresas obtêm vantagem competitiva em ambientes dinâmicos (Wang \& Ahmed, 2007; Ambrosini \& Bowman, 2009).

O conceito de CDs aborda a identificação de oportunidades, a formulação e a implementação de ações organizacionais. Diz respeito a identificar não apenas o que fazer, mas como e quando fazer (Helfat $e t$ al., 2007). As capacidades podem ser divididas em organizacionais e dinâmicas. Enquanto aquelas sustentam as empresas no presente, estas dizem respeito à mudança e à sustentação organizacional no longo prazo (Winter, 2003; Helfat et al., 2007). CDs estão vinculadas a ações propositais, ou seja, envolvem desejo de estender e modificar a base de recursos da organização, visando ao constante realinhamento empresa-ambiente (Helfat \& Peteraf, 2009).

As CDs são competências de alto nível que determinam a habilidade de uma empresa para desenvolver, integrar e reconfigurar competências e recursos internos e externos, a fim de ajustar-se a, ou de influenciar, ambientes de negócios caracterizados por altas turbulências, de ordem econômica, tecnológica ou concorrencial (Teece, 2012). CDs são difíceis de serem implantadas nas empresas, na medida em que estão relacionadas a ativos intangíveis, encontrados em ambientes competitivos complexos e turbulentos, os quais demandam mudança constante. A compreensão dos mecanismos geradores de CDs e a sua adequada implantação nas empresas tendem a contribuir para a melhor adaptação das organizações às novas demandas impostas pelo ambiente de negócios (Guerra, Tondolo \& Camargo, 2016).

Duas correntes principais de definições e de elementos são identificadas na literatura sobre CDs: i) a que classifica CDs como conjunto de capacidades e habilidades e, ii) a que classifica CDs como conjunto de rotinas e processos.

Dentre os autores que classificam CDs como capacidades e habilidades pode-se destacar Collis (1994), Andreva e Chaika (2006), Marcus e Anderson (2006), Zahra, Sapienza e Davidson (2006), Wang e Harmed (2007), Helfat et al. (2007) e McKelvie e Davidson (2009).
Para Collis (1994), a perpetuação bemsucedida do negócio é dependente da capacidade organizacional de inovar de forma mais rápida e melhor que os concorrentes. Para o referido autor, a vantagem competitiva não decorre da inovação em si, mas sim da capacidade de constantemente desenvolver estruturas de negócio que favoreçam a renovação continuada do mesmo.

Marcus e Anderson (2006) definem CDs como a habilidade de renovar, ampliar e adaptar competências ao longo do tempo. Neste mesmo sentido, Zahra, Sapienza e Davidson (2006) consideram CDs como a habilidade organizacional de reconfigurar recursos e rotinas da empresa da maneira prevista e idealizada pelo principal gestor da organização.

Por sua vez, para Andreva e Chaika (2006), CDs podem ser definidas com um conjunto de propriedades / características organizacionais que proporcionam a renovação das capacidades organizacionais principais, à medida em que mudanças acontecem no ambiente competitivo.

Wang e Ahmed (2007), definem capacidades dinâmicas como um comportamento orientado, de forma constante, para integrar, reconfigurar, renovar e recriar recursos e capacidades organizacionais. Para os referidos autores, capacidades dinâmicas não são apenas processos, mas estão incorporadas nos processos organizacionais. Capacidades dinâmicas são específicas da empresa e são desenvolvidas, com o tempo, através de complexas interações entre os recursos da firma. O comportamento orientado e constante ressalta a necessidade de comprometimento da alta administração e o compromisso com algo a ser realizado ao longo do tempo, não apenas eventualmente.

McKelvie e Davidson (2009) conceituam capacidades dinâmicas como um conjunto de capacidades que envolvem a geração de novas ideias, a habilidade de desenvolver produtos, serviços e processos inovadores e superiores àqueles apresentados pela concorrência, bem como a capacidade de provocar rupturas e dinamismo no mercado. Como pode ser observado, a definição apresentada pelos autores não reporta apenas a necessidade de adaptação, mas contempla, também, a possibilidade de ser agente da mudança.

Dentre os autores que classificam CDs como conjunto de rotinas e processos, destacam-se os autores Eisenhardt e Martin (2000), Zollo e Winter (2002), Alsos et al. (2008), Teece (2007), Ambrosini e Bowman (2009) e Tondolo e Bitencourt (2014).

Para Eisenhardt e Martin (2000), o padrão estrutural das CDs varia de acordo com o dinamismo do mercado. Assim, mercados moderadamente competitivos aceitam CDs que envolvem padrões de procedimentos mais incrustados, relacionados ao desenvolvimento de processos organizacionais perfeitamente identificáveis, tais como rotinas de desenvolvimento de produtos e de desenvolvimento de 
alianças, que permitem às empresas identificar, aplicar e replicar conhecimento. No caso de mercados mais dinâmicos, as rotinas tornam-se frágeis, mudam com maior frequência, e isso exige mais das organizações em termos de adaptação. Para os autores, são os recursos que, se adequadamente configurados e reconfigurados de acordo com as novas exigências, garantem vantagem competitiva de longo prazo. Neste sentido, Eisenhardt e Martin (2000) consideram que CDs são rotinas organizacionais e estratégicas, por meio das quais as organizações obtêm novas configurações de recursos, à medida que mercados emergem, evoluem e morrem.

Zollo e Winter (2002), consideram que CDs envolvem um padrão estável de atividades coletivas, através das quais as empresas, de modo sistemático, geram e modificam suas rotinas operacionais em busca de maior eficácia. Para os referidos autores, a ênfase das CDs está nos padrões e nos processos organizacionais de aprendizado. É destes processos de aprendizado que emergem as CDs e as mesmas vão sendo aperfeiçoadas, com o tempo, à medida em que o aprendizado evolui.

Para Teece (2007), as CDs dizem respeito a atividades de nível superior que evidenciam a habilidade da gestão organizacional em monitorar o ambiente e perceber oportunidades e ameaças. Dizem respeito, também, a agir para aproveitar as oportunidades e atenuar as ameaças, a configurar os recursos organizacionais, tendo como objetivo atender às novas necessidades dos clientes e a buscar adaptação evolutiva constante. Essa constante e adequada renovação do negócio resultará, segundo o autor, em criação de valor no longo prazo para a empresa e seus investidores.

Alsos et al. (2008), destacam CDs como mecanismos e processos organizacionais que permitem às organizações construir, reconfigurar, integrar, reorganizar e eliminar recursos e capacidades, com a finalidade de acompanhar as mudanças nos requisitos competitivos.

Por sua vez, para Ambrosini e Bowman (2009) CDs não são classificadas como capacidades, competências ou recursos organizacionais, reportandose à categorização aplicada pela RBV. Seriam, pois, processos organizacionais que têm impacto positivo sobre a base de recursos organizacionais.

Neste mesmo sentido, Tondolo e Bitecourt (2014) consideram CDs não como uma capacidade específica, mas, sim, como um conjunto de processos que habilitam a organização a lidar com as mudanças do ambiente de negócios. Para os referidos autores, CDs são formadas por conjuntos de processos que têm efeito sobre a base de recursos e capacidades das organizações. Assim, o desenvolvimento de recursos e capacidades, importantes para a renovação do negócio e sua consequente sustentação no longo prazo, é resultado das CDs.

Há ainda, autores que consideram que CDs envolvem tanto conjuntos de habilidades, como conjuntos de atitudes e processos organizacionais. Neste sentido, Meirelles e Camargo (2014) conceituam Capacidades Dinâmicas como "a capacidade que é baseada em decisões deliberadas e recorrentes, composta por processos combinatórios de capacidades que permitem criar, estender, modificar ou reconfigurar as capacidades-chave da organização e sua base de recursos e competências" (p.56). Deliberadas porque as decisões envolvendo CDs são tomadas de forma organizada, proposital, consciente. Recorrentes, porque fazem parte das rotinas do negócio, não são algo eventual.

Para Meirelles e Camargo (2014), capacidades dinâmicas envolvem mais do que conjuntos de habilidades e processos. Envolvem comportamentos e habilidades que favoreçam a mudança e a inovação, processos e rotinas de busca da inovação e mecanismos de aprendizagem e de governança do conhecimento. Para os referidos autores, os mecanismos de governança do conhecimento dão suporte à existência das capacidades dinâmicas.

Meirelles e Camargo (2014) reportam-se, ainda, aos indicadores da existência de capacidades dinâmicas nas organizações: (i) geração de ideias e introdução de rupturas no mercado; (ii) as mudanças organizacionais e (iii) inovação e o desenvolvimento de novos mercados. Assim, quanto mais desenvolvidas as CDs na organização, maior o reflexo percebido nos indicadores propostos pelos autores. 
Figura 1- Modelo Integrado de Capacidades Dinâmicas: Comportamentos, Habilidades, Processos e Mecanismos de Aprendizagem e Governança do Conhecimento.



Fonte: Meirelles e Camargo (2014).

Como observado por diferentes autores, a abordagem das CDs foca o papel da gestão em construir e adaptar competências como forma de ajustar a organização às rápidas mudanças que ocorrem no ambiente de negócios. O elemento que diferencia o modelo das CDs de outras concepções é o foco na habilidade organizacional/gerencial de identificar a mudança, compreender o reflexo da mudança sobre a base de recursos e competências organizacionais, e agir no sentido de buscar a sua reconfiguração (Harreld $e t$ al., 2007).

Para Harreld et al., (2007), o desenvolvimento e a aplicação de CDs exigem da gerência de nível superior o desenvolvimento de habilidades consideradas essenciais para a renovação do negócio. Exige a habilidade de adequadamente perceber a mudança (sense) no ambiente competitivo, fato que pode envolver questões tecnológicas, de competição, de alterações nas necessidades e nos desejos dos clientes, entre outras. Também exige a habilidade de apropriar-se (seize) e agir de modo correto para aproveitar eventuais oportunidades e minimizar as ameaças, via reconfiguração de recursos e competências organizacionais. Para os autores, essas habilidades - perceber, apropriar-se e agir representam a essência das CDs.

Já para Teece (2012), CDs podem ser classificas em três grandes categorias: 1) identificação e avaliação de oportunidades (sensing); 2) mobilização de recursos para beneficiar-se da oportunidade identificada (seizing); 3) renovação continuada (transforming). Para o autor, essas três atividades devem ser desenvolvidas de modo superior, se a empresa deseja sustentar-se à medida que os mercados e as tecnologias mudam e evoluem.

A essência do crescimento sustentável da lucratividade da empresa reside na habilidade da gerência de nível superior em recombinar e reconfigurar estruturas e ativos organizacionais, à medida que os mercados evoluem e novas tecnologias surgem (Harreld et al., 2007). Assim, para sustentar CDs, a gerência superior deve possuir habilidades desenvolvidas para identificar oportunidades, mobilizar recursos para beneficiar-se da oportunidade e assegurar a renovação contínua do negócio (Teece, 2012).

A leitura do referencial teórico sobre CDs sugere que, em ambientes competitivos complexos e turbulentos, a renovação organizacional é uma necessidade. A contribuição das CDs para a renovação organizacional ocorre mediante o desenvolvimento de habilidades e a implementação de processos que permitam identificar oportunidades e ameaças e reconfigurar, de modo intencional, os ativos organizacionais, de forma a atender as novas necessidades do ambiente competitivo.

\section{PROCEDIMENTOS METODOLÓGICOS}

Este estudo tem como abordagem metodológica a pesquisa qualitativa. Os dados que fundamentaram a pesquisa foram coletados de fontes primárias e secundárias. Os dados primários foram obtidos mediante a realização de entrevistas em profundidade com 14 profissionais com expertise em IC, notadamente nas áreas acadêmica e de consultoria. O número de entrevistados foi considerado suficiente, na medida em que as respostas começaram a indicar convergência de opiniões. Optou-se por realizar a pesquisa com profissionais envolvidos com a atividade de consultoria, e não diretamente com profissionais que desenvolvem a atividade de IC como executivos de empresas, tendo como objetivo minimizar o viés positivo do respondente. Acredita-se que uma visão externa às empresas está mais propícia ao fornecimento de respostas fidedignas, já que não há o compromisso direto com o desenvolvimento a contento da atividade nas respectivas organizações, como ocorreria caso o questionamento fosse realizado diretamente a executivos de IC das empresas. Esse procedimento 
A Inteligência Competitiva e o Desenvolvimento de Capacidades Dinâmicas nas Organizações

encontra amparo no referencial teórico sobre IC. De acordo com Wright e Calof (2006), investigações sobre o atual estágio das práticas de IC devem ser realizadas de forma indireta, já que poucas empresas se prestariam a fornecer informações detalhadas e fidedignas sobre o estágio de desenvolvimento da atividade em seus departamentos. Reforçando essa afirmação, Reinmoeller e Ansari (2016) identificaram que muitas empresas desenvolvem a atividade de IC, mas se recusam a reconhecer publicamente tal fato e procuram mantê-la meio nebulosa, escondida, realizada de forma não clara, pois consideram a existência de certo risco de serem estigmatizadas devido à adoção da prática.

Os profissionais foram acessados pelo pesquisador depois de ampla investigação a respeito de autores de artigos na área de IC (revistas científicas especializadas em IC ou inteligência de mercado), bem como de livros sobre o tema. Foram acessados diretamente, via e-mail, nove possíveis entrevistados. Três não deram retorno ao contato inicial. Os seis que restaram fizeram outras indicações de profissionais com expertise na área, os quais foram contatados pelo pesquisador. Todos os entrevistados são consultores na área de IC e já assessoram, ou assessoraram, grandes organizações brasileiras em matéria de IC, inteligência de mercado e planejamento estratégico, contemplando empresas de todo o território brasileiro. O Quadro 2 caracteriza os entrevistados. Optou-se por não revelar seus nomes para manter o sigilo acerca da fonte de informação. De acordo com Heneman (1974), a chance de obter-se respostas livres de viés é maior quando os pesquisados têm o seu anonimato assegurado.

\begin{tabular}{|c|c|}
\hline CODIFICAÇÃO & CARACTERIZAÇÃO \\
\hline E1 - Entrevistado 1 & $\begin{array}{l}\text { Consultor na área de IC. Pesquisador da área. Autor de artigos e livros na área. } \\
\text { Palestrante. Professor universitário. Ex-diretor regional de organização } \\
\text { representativa da IC. Formação acadêmica em nível de doutorado. }\end{array}$ \\
\hline E2 - Entrevistado 2 & $\begin{array}{l}\text { Consultor na área de IC. Pesquisador da área. Autor de artigos sobre IC. } \\
\text { Palestrante. Professor universitário. Formação acadêmica em nível de mestrado. }\end{array}$ \\
\hline E3 - Entrevistado 3 & $\begin{array}{l}\text { Consultor na área de IC. Pesquisador da área. Autor de artigos e livros sobre IC. } \\
\text { Palestrante. Formação acadêmica em nível de doutorado. }\end{array}$ \\
\hline E4 - Entrevistado 4 & $\begin{array}{l}\text { Consultor na área de IC. Pesquisador da área. Autor de artigos e livros na área. } \\
\text { Palestrante. Professor universitário. Ex-diretor regional de organização } \\
\text { representativa da IC. Formação acadêmica em nível de doutorado. }\end{array}$ \\
\hline E5 - Entrevistado 5 & $\begin{array}{l}\text { Consultor na área de IC. Pesquisador da área. Autor de artigos na área. } \\
\text { Professor universitário. Formação acadêmica em nível de doutorado. }\end{array}$ \\
\hline E6 - Entrevistado 6 & $\begin{array}{l}\text { Consultor na área de IC. Palestrante. Professor universitário. Formação } \\
\text { acadêmica em nível de doutorado. }\end{array}$ \\
\hline E7 - Entrevistado 7 & $\begin{array}{l}\text { Consultor na área de IC. Palestrante. Professor universitário. Formação } \\
\text { acadêmica em nível de mestrado. }\end{array}$ \\
\hline E8 - Entrevistado 8 & $\begin{array}{l}\text { Consultor na área de IC. Palestrante. Autor de artigos e de livros na área. } \\
\text { Diretor regional de organização representativa da IC. Formação acadêmica em } \\
\text { nível de mestrado. }\end{array}$ \\
\hline E9 - Entrevistado 9 & $\begin{array}{l}\text { Consultor na área de IC. Palestrante. Autor de livros na área. Formação } \\
\text { acadêmica em nível de graduação com vários cursos de especialização na área, } \\
\text { modalidade latu senso, realizados no exterior. }\end{array}$ \\
\hline $\begin{array}{l}\text { E10 - Entrevistado } \\
10\end{array}$ & $\begin{array}{l}\text { Consultor na área de IC. Palestrante. Diretor regional de organização } \\
\text { representativa da IC. Formação acadêmica em nível de doutorado. }\end{array}$ \\
\hline $\begin{array}{l}\text { E11 - Entrevistado } \\
11\end{array}$ & $\begin{array}{l}\text { Consultor na área de IC. Palestrante. Formação acadêmica em nível de } \\
\text { mestrado. }\end{array}$ \\
\hline $\begin{array}{l}\text { E12 - Entrevistado } \\
12\end{array}$ & $\begin{array}{l}\text { Consultor na área de IC. Palestrante. Formação acadêmica em nível de } \\
\text { mestrado. }\end{array}$ \\
\hline $\begin{array}{l}\text { E13 - Entrevistado } \\
13\end{array}$ & $\begin{array}{l}\text { Consultor na área de IC. Palestrante. Ex-diretor regional de organização } \\
\text { representativa da IC. Formação acadêmica em nível de mestrado. }\end{array}$ \\
\hline $\begin{array}{l}\text { E14 - Entrevistado } \\
14\end{array}$ & $\begin{array}{l}\text { Consultor na área de IC. Palestrante. Formação acadêmica em nível de } \\
\text { mestrado. }\end{array}$ \\
\hline
\end{tabular}

Quadro 2 - Caracterização dos entrevistados Fonte: elaborado pelo autor. 
As informações secundárias, por sua vez, foram obtidas por meio de consultas a artigos publicados sobre o assunto em revistas científicas, trabalhos realizados por outros pesquisadores, entrevistas fornecidas para diferentes meios de comunicação por profissionais da área sobre o tema, dissertações de mestrado e tese de doutorado sobre IC. $\mathrm{O}$ acesso a variadas fontes de informação permitiu a realização de triangulação de informações, melhorando, assim, a credibilidade e, por consequência, a confiabilidade dos resultados (Ulrich, Oliveira, Basso \& Visentini, 2012).
As entrevistas tiveram duração aproximada de 60 minutos. Um roteiro flexível de entrevistas foi elaborado, contemplando, entre outros aspectos, as fases do ciclo de IC. O referido roteiro foi testado antes da sua efetiva aplicação. Depois de procedidos os ajustes considerados necessários, realizam-se as entrevistas, as quais foram gravadas e transcritas, tendo como objetivo a sua preservação como importante fonte de informação. A Figura 2 evidencia o roteiro adotado para a elaboração da pesquisa.

Figura 2 - Roteiro adotado para a pesquisa

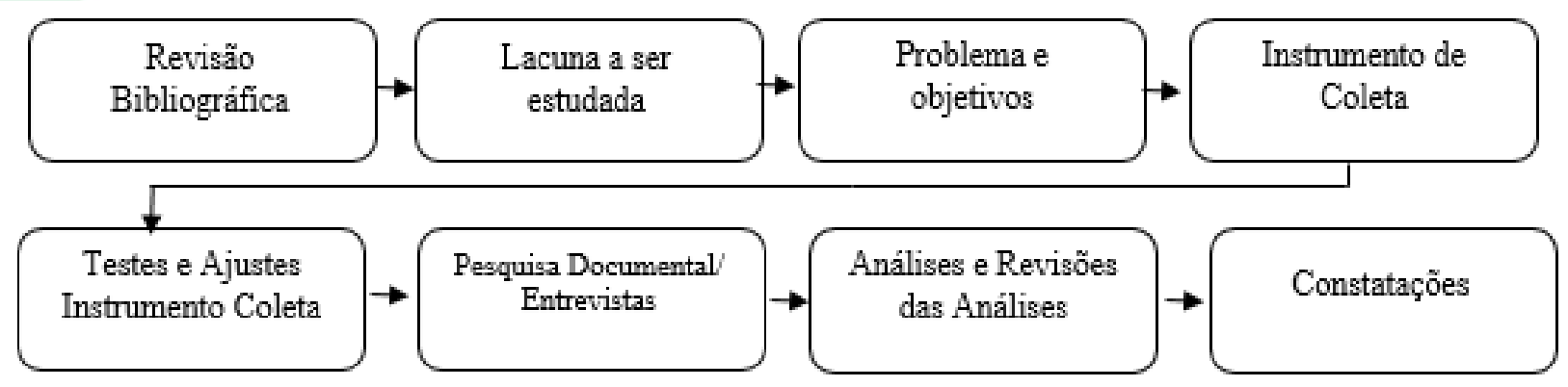

Fonte: Elaborado pelo autor

O exame dos dados foi realizado mediante a aplicação da técnica de análise de conteúdo. Para tanto, foram criadas, a priori (Bardin, 2009; Franco, 2007), 10 categorias de análise, contemplando as fases do ciclo de IC e outras variáveis de interesse para a pesquisa (Quadro 3). Considera-se que o ciclo de IC é um bom instrumento para avaliar o estágio de desenvolvimento das práticas de IC. O referido ciclo de IC já foi aplicado em outros estudos que tiveram como objetivo avaliar práticas de IC (Rangel, 2006).

\begin{tabular}{|l|l|}
\hline \multicolumn{1}{|c|}{ CATEGORIA DE ANÁLISE } & \multicolumn{1}{|c|}{ DESCRIÇÃo } \\
\hline C1 - Planejamento & $\begin{array}{l}\text { Definição dos produtos de IC desejados; definição dos cursos de } \\
\text { ação que serão adotados para a busca de informações; início do } \\
\text { ciclo de IC. }\end{array}$ \\
\hline C2 - Coleta & $\begin{array}{l}\text { Garimpo, busca de informaç̃̃es, transformação de matéria prima } \\
\text { em informação. Processamento e armazenamento da informação. }\end{array}$ \\
\hline C3 - Análise & $\begin{array}{l}\text { Fase mais complexa do ciclo de IC. Habilidade, inteligência } \\
\text { humana. Consideração de informações, busca de padrões, } \\
\text { estabelecimento de relacionamentos, desenvolvimento de } \\
\text { cenários baseados no que foi coletado. }\end{array}$ \\
\hline C4 - Disseminação & $\begin{array}{l}\text { Distribuição, entrega e acessibilidade dos produtos de IC aos } \\
\text { interessados. Momento em que o profissional de IC deve sugerir } \\
\text { cursos de ação. }\end{array}$ \\
\hline C5 - Uso & $\begin{array}{l}\text { Efetiva aplicação para fins táticos ou estratégicos dos produtos } \\
\text { da IC. }\end{array}$ \\
\hline C6 - Redes de inteligência & $\begin{array}{l}\text { Formação de redes de informação buscando o fluxo mais fluido } \\
\text { tanto de dados brutos como dos produtos de inteligência. }\end{array}$ \\
\hline C7 - Estrutura da área & Estrutura física, tecnológica e humana destinada à área de IC. \\
\hline C8 - Localização no organograma & $\begin{array}{l}\text { Categoria autoexplicativa. Posição/localização da área de IC no } \\
\text { organograma empresarial. }\end{array}$ \\
\hline
\end{tabular}




\begin{tabular}{|l|l|}
\hline C9 - Compartilhamento de informações & $\begin{array}{l}\text { Existência de incentivo organizacional e de processos que } \\
\text { facilitem o compartilhamento de informações entre os usuários } \\
\text { dos produtos de IC. }\end{array}$ \\
\hline C10 - Comparações & $\begin{array}{l}\text { Relato de diferenças de práticas entre empresas localizadas no } \\
\text { Brasil, nos Estados Unidos e em países desenvolvidos da } \\
\text { Europa, como Alemanha, Inglaterra e França. }\end{array}$ \\
\hline
\end{tabular}

Quadro 3 - Categorias de análise

Fonte: elaborado pelo autor.

Para a realização do procedimento de categorização dos dados coletados, foram desenvolvidos quadros analíticos tendo como objetivo sintetizar as informações consideradas mais importantes, realizar cruzamentos e facilitar achados.
Como se pode observar no exemplo (Quadro 4), os referidos quadros continham informações sobre a categoria, o quesito formulado, a informação apresentada pelo respondente e a triangulação possível encontrada em fontes secundárias de informação.

\begin{tabular}{|l|l|l|l|l|}
\hline CATEGORIA & QUESITO & CONSTATAÇÃO & FONTE & TRIANGULAÇÃO \\
\hline & & & & \\
\hline
\end{tabular}

Quadro 4 - Quadro auxiliar aplicado na análise Fonte: elaborado pelo autor.

\section{ANÁLISE}

Como destacado na introdução, dois objetivos nortearam a execução do presente estudo: i) estudar os conceitos de inteligência competitiva e capacidades dinâmicas, buscando identificar se as etapas do ciclo de inteligência competitiva podem se constituir em elementos mobilizadores de capacidades dinâmicas nas organizações e, ii) identificar como se encontra o processo de inteligência competitiva nas organizações brasileiras de médio e grande porte, tendo como base a opinião de especialistas sobre o tema. Para melhor atender estes objetivos, dividiu-se o capítulo de análise em duas partes respectivas.

\subsection{Discussão do potencial contributivo das etapas do ciclo de IC para a mobilização de CDs}

A análise do referencial teórico apresentado sugere que, em ambientes competitivos, complexos e turbulentos, a renovação organizacional é uma necessidade (Teece et al.,1997; Eisenhardt \& Martin, 2000; Harreld et al., 2007; Ambrosini \& Bowman, 2009; Teece, 2012). A contribuição das CDs para a renovação organizacional ocorre mediante a implementação de processos (Eisenhardt \& Martin, 2000; Zolo \& Winter, 2002; Teece, 2007; Alsos et al., 2008; Ambrosini \& Bowman, 2009; Tondolo \& Bitencourt, 2014) e o desenvolvimento de habilidades (Collis, 1994; Marcus \& Anderson, 2006; Zahra et al., 2006; Wang \& Ahmed, 2007; McKelvie \& Davidson, 2009) que permitam identificar oportunidades e ameaças e reconfigurar, de modo intencional, no tempo certo e da forma adequada, os ativos organizacionais (Teece et al., 1997; Eisenhardt \& Martin, 2000; Ambrosini \& Bowman, 2009).
Requisitos do ambiente em mudança e dinamismo do mercado, sugerem que as organizações que enfrentam ambientes mais dinâmicos estão mais suscetíveis ao desenvolvimento de CDs. Neste sentido Drnevich e Kriauciunas (2011), bem como Molina, Bustinza e Guitiérrez-Gutiérrez (2013) identificaram que o dinamismo ambiental afeta positivamente o desenvolvimento de CDs nas organizações.

A literatura também enfoca a importância do ambiente interno. Eisenhardt e Martin (2000) destacam que processos internos são elementos que alavancam o desenvolvimento de CDs. O reconhecimento por parte dos gestores de uma oportunidade a aproveitar (Montealegre, 2002) e a gestão empreendedora (Teece, 2007) são, também, exemplos de como o ambiente interno é considerado importante para o desenvolvimento de CDs.

Para Harreld et al., (2007), o desenvolvimento e a aplicação de CDs pela gerência de nível superior requerem o desenvolvimento de duas habilidades: a de adequadamente perceber a mudança (sense), bem como a de apropriar-se e agir (seize) de modo correto para aproveitar eventuais oportunidades e minimizar as ameaças, via reconfiguração de recursos e competências organizacionais. Para os referidos autores, é nessas habilidades (sense e seize) que reside a essência das CDs.

Teece (2012) também se reporta à identificação e à avaliação de oportunidades (sensing), bem como à mobilização de recursos para o aproveitamento das oportunidades (seizing) ao referirse ao tema CD. O referido autor, entretanto, destaca, também, a necessidade da renovação continuada do negócio (transforming). 
A análise do referencial teórico sobre IC, por sua vez, também identificou a necessidade de constante monitoramento do ambiente de negócios, tendo como objetivo emitir alertas antecipados para a gestão superior quanto a eventuais oportunidades e ameaças. Assim, como no caso das CDs, ambientes competitivos mais dinâmicos e estruturas internas adequadamente disponibilizadas, também foram identificados como elementos que incentivam o desenvolvimento da atividade de IC (Jin \& Bouthillier, 2013).

O referencial teórico sobre IC apresentado neste estudo evidenciou que os autores se reportam ao ciclo de inteligência como a unidade básica do sistema de inteligência. Para Kahaner (1997), Pirtila (1998) e Miller (2002) o ciclo de inteligência contempla quatro fases, envolvendo o planejamento, a coleta, a análise e a disseminação da inteligência. Já para Sharp (2009) o ciclo contempla, também, a fase do efetivo uso da informação. Considera-se que o referido uso pode ser entendido como a mobilização de esforços no sentido de beneficiar-se da inteligência gerada pela atividade de IC.

Se o desenvolvimento de CDs e o seu estabelecimento como processo capaz de reconfigurar a base de recursos organizacionais requer que as organizações sejam capazes de perceber a mudança que está ocorrendo (sensing), tenham a capacidade de mobilizar recursos para o adequado aproveitamento de oportunidades identificadas (seizing) e sejam capazes de continuadamente renovar as rotinas do negócio (transforming), então a atividade de IC desempenha papel central neste processo, pois cabe à IC identificar as necessidades de informação (planejamento), realizar a busca da informação (coleta), transformar a informação em inteligência (análise), entregar os produtos de inteligência aos tomadores de decisão (disseminação) e trabalhar para favorecer a aplicação dos produtos da inteligência nas decisões organizacionais (uso).

Figura 3 - Relação entre IC e o desenvolvimento de CDs

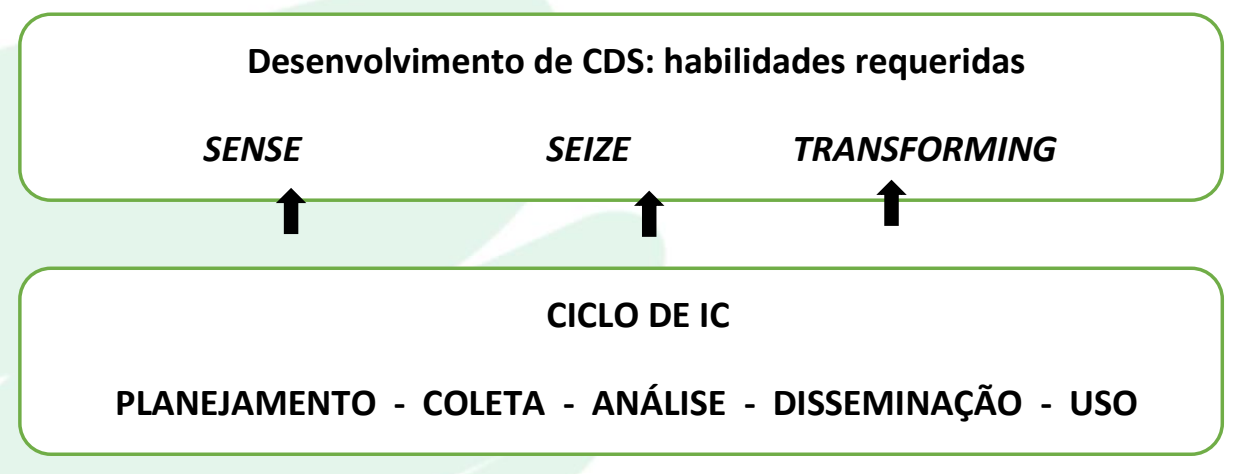

Fonte: elaborado pelo autor.

Para manterem-se competitivas, anteciparemse ou reagirem às mudanças que ocorrem em seu setor, e no ambiente de negócios, de modo mais amplo, as empresas precisam de processos organizacionais que lhes permitam transformar dados em inteligência acionável, da qual derivarão decisões táticas e estratégicas (Nikolaos \& Evangelia, 2012). A IC, mediante o emprego das etapas que compõem o ciclo de inteligência, pode ser considerada como uma disciplina de gestão que possibilita que os executivos tomem decisões mais inteligentes, com maior probabilidade de sucesso, favorecendo o desenvolvimento da decisão correta, já na primeira vez. Uma visão mais focada da IC, considera-a como a função organizacional responsável pela antecipada identificação de riscos e oportunidades no mercado, antes que tais riscos e oportunidades se tornem óbvios (Sharp, 2009).

Ademais, renovar a base de recursos organizacionais e desenvolver processos que favoreçam o desenvolvimento de CDs têm sido uma preocupação na área de estratégia (Eisenhardt \&
Martin; 2000; Danneels, 2010). Dessa forma, a análise das práticas de IC pode não só ajudar a inferir o quão desenvolvido está a IC numa organização, mas também gerar insights sobre o estágio de maturidade dos seus processos geradores de CDs e sobre suas possibilidades de adaptação às novas demandas do ambiente de negócios.

Defende-se, dessa forma, que as rotinas de IC e as habilidades requeridas para a sua operacionalização, fazem parte do conjunto de processos e habilidades demandados para o desenvolvimento e a operacionalização de CDs nas organizações. A IC, mediante o correto desenvolvimento das atividades estabelecidas em suas fases (planejamento, coleta, análise, disseminação e uso), age no sentido de favorecer a percepção da mudança (sense) e de fornecer a inteligência necessária à apropriação do conhecimento que servirá de base para a ação (seize), contribuindo, assim, para o desenvolvimento de capacidades favorecedoras da continuada renovação do negócio (transforming). Para aproveitar oportunidades e minimizar riscos, primeiro é 
necessário percebê-los, identificá-los corretamente, depois agir no sentido de avaliar e definir cursos de ação. As etapas do clico de IC contribuem sobremaneira neste sentido. O Quadro 5 busca evidenciar como cada uma das etapas do ciclo de IC favorece o desenvolvimento de CDs.

\begin{tabular}{|c|c|c|c|}
\hline Ciclo da IC & Descrição & \multicolumn{2}{|c|}{ Como favorece o desenvolvimento de CDs. } \\
\hline Planejamento & 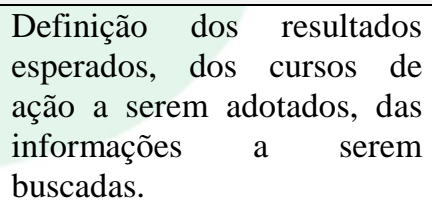 & $\begin{array}{l}\text { Proporciona aos gestores a oportunidade } \\
\text { de pensar sobre a concorrência e o } \\
\text { ambiente de negócios, a discutir } \\
\text { informações necessárias para ampliar seu } \\
\text { conhecimento sobre tais itens. }\end{array}$ & \multirow{3}{*}{ Sensing } \\
\hline Coleta & $\begin{array}{l}\text { Busca e transformação de } \\
\text { dados em informação }\end{array}$ & $\begin{array}{l}\text { Incentiva a curiosidade organizacional, } \\
\text { chama a atenção para acontecimentos. }\end{array}$ & \\
\hline Análise & $\begin{array}{l}\text { Busca por padrões, } \\
\text { relacionamentos, } \\
\text { desenvolvimento } \\
\text { cenários. Transformação da } \\
\text { informação em inteligência. } \\
\end{array}$ & $\begin{array}{l}\text { Proporciona alertas antecipados, a } \\
\text { descoberta de padrões, de relacionamentos. } \\
\text { Favorece a discussão de cenários } \\
\text { competitivos. }\end{array}$ & \\
\hline Disseminação & $\begin{array}{l}\text { Entrega dos produtos da IC } \\
\text { aos interessados. Cursos de } \\
\text { ação são discutidos. }\end{array}$ & $\begin{array}{l}\text { Oferece inteligência aos gestores. Chama a } \\
\text { atenção sobre padrões e relacionamentos. } \\
\text { Dá a oportunidade para a criatividade } \\
\text { entrar em ação. Momento em que a } \\
\text { organização se apropria do conhecimento } \\
\text { gerado pela IC. }\end{array}$ & Seizing \\
\hline Uso & $\begin{array}{l}\text { Efetiva aplicação para fins } \\
\text { táticos e estratégicos dos } \\
\text { produtos da IC }\end{array}$ & $\begin{array}{l}\text { Se bem aplicados, os produtos da IC, } \\
\text { quando colocados em prática, contribuirão } \\
\text { para a renovação do negócio. }\end{array}$ & Transforming \\
\hline
\end{tabular}

Quadro 5 - Ciclo de IC e o desenvolvimento de CDs

Fonte: desenvolvido pelo autor

Mesmo quando se leva em consideração modelos integrados envolvendo o conceito de CDs, como o apresentado por Meirelles e Camargo (2014), verificase que, ainda assim, se constata associação entre as etapas do ciclo de IC e o desenvolvimento de CDs.

Como reportado no referencial teórico, Meirelles e Camargo (2014) destacam como elementos componentes das CDs os comportamentos e habilidades de mudança e inovação (comportamentos como lealdade e comprometimento com a mudança; habilidades como as de identificar oportunidades de mercado, de reconhecer o valor de tais oportunidades e de aproveitá-las comercialmente), os processos e rotinas que favoreçam a busca da inovação (rotinas de pesquisa e desenvolvimento e rotinas de delineamento de soluções para clientes, dentre outras) e a existência de mecanismos de aprendizagem e governança do conhecimento (mecanismos que dão sustentação à existência de CDs).

Como atividade que trata, de maneira organizada e sistemática, da busca de informações, da transformação de tais informações em inteligência e da geração de alertas antecipados sobre oportunidades e ameaças, a IC contribui para o desenvolvimento de posturas que reconheçam a inovação como uma necessidade, incentiva o estabelecimento de processos de inovação e requer a aplicação de mecanismos favorecedores da aprendizagem, bem como do adequado gerenciamento do conhecimento. O transforming, reportado por Teece (2012) como a necessidade de renovação continuada do negócio, só ocorrerá se houver o adequado gerenciamento do conhecimento, como reportado por Meirelles e Camargo (2014). Contempla, portanto, os elementos componentes das CDs, e, como tal, tem potencial para evidenciar reflexos nos indicadores de sua existência, como exposto no modelo integrado de Meirelles e Camargo (2014).

A denominação destinada a atividade não é importante e, sim, a aplicação de seus ciclos. Tenha a denominação que tiver (Inteligência Competitiva, Inteligência de Mercado, Inteligência de Marketing, etc.), as atividades de planejar a busca de informações, de coletar o que foi discutido e determinado como importante, de analisar, disseminar e efetivamente empregar, para fins táticos e, muito mais importante para a longevidade do negócio, para fins estratégicos, contribuem decisivamente para o desenvolvimento de CDs nas organizações.

Logo, dedicar mais atenção às etapas do ciclo de IC, favorecendo o seu desenvolvimento dentro das organizações (desenvolvimento de cultura organizacional que favoreça a atividade, adequado fornecimento de estrutura e de recursos, 
desenvolvimento de pessoas habilitadas à função, fortalecimento de redes de inteligência) são procedimentos favorecedores do desenvolvimento de CDs e, por consequência, da transformação do negócio, dando mais condições à busca de vantagem competitiva e à preservação organizacional no longo prazo.

\subsection{Estudo das práticas de IC}

Uma vez defendida a posição de que as etapas do ciclo de inteligência favorecem a renovação do negócio, constituindo-se, portanto em processos que favorecem o desenvolvimento de CDs, passa-se estudar as práticas de IC.
Como destacado na introdução, o presente trabalho também tem como objetivo identificar como se encontra o processo de IC nas organizações brasileiras de médio e grande porte, tendo como base a opinião de especialistas sobre o tema. Para evitar a apresentação excessiva de declarações realizadas pelos entrevistados, elaborou-se o Quadro 6, no qual se destacam algumas observações apresentadas, as categorias aplicadas durante o processo de categorização, bem como a fonte. Após a apresentação do referido quadro, são realizados comentários, merecendo destaque os insights gerados pelo processo de análise.

\begin{tabular}{|c|c|c|}
\hline CATEGORIA & OBSERVAÇÃO/CONSTATAÇÃO & Fonte \\
\hline C1 - Planejamento & $\begin{array}{l}\text { Há falhas já na fase inicial do processo. Há um esforço para identificar } \\
\text { quem são os usuários, mas apenas um subconjunto de usuários é } \\
\text { atendido. Não está claro para a maioria das empresas as necessidades de } \\
\text { informação. Muitas informações ainda seguem um processo ad hoc. }\end{array}$ & $\begin{array}{l}\text { E1; E3; E4; } \\
\text { E5; E6; E8. }\end{array}$ \\
\hline C2 - Coleta & $\begin{array}{l}\text { A coleta de informação está funcionando bem, apesar das falhas no } \\
\text { planejamento. O uso da informação deixa a desejar. É uma prática } \\
\text { regular em muitas grandes empresas brasileiras. Existe muita coleta e } \\
\text { pouca leitura do que é coletado. Falta tempo para analisar. Falta método, } \\
\text { olhar a cadeia como um todo. As empresas de IC trabalham muito bem } \\
\text { esta questão. }\end{array}$ & $\begin{array}{l}\mathrm{E} 1 ; \mathrm{E} 2 ; \mathrm{E} 4 ; \\
\mathrm{E} 5 ; \mathrm{E} 7 ; \mathrm{E} 8 \\
\mathrm{E} 10\end{array}$ \\
\hline C3 - Análise & $\begin{array}{l}\text { Há carência de profissionais bem preparados. Profissionais de outras } \\
\text { áreas desempenham a função, e isto prejudica o desempenho. Não há } \\
\text { geração de insights. Há um descolamento das etapas anteriores. Muita } \\
\text { coleta, pouca leitura. Falta tempo. Falta método. }\end{array}$ & $\begin{array}{l}\text { E1; E2; E4; } \\
\text { E6; E7; E8; } \\
\text { E12 }\end{array}$ \\
\hline C4 - Disseminação & $\begin{array}{l}\text { Não é comum a apresentação de sugestões pela equipe de IC. Há um } \\
\text { descolamento entre a geração de informação e a apresentação de } \\
\text { recomendações práticas. Há apenas a apresentação de dados. É uma } \\
\text { etapa que precisa ser melhor desenvolvida. Não participam das reuniões } \\
\text { de planejamento. Não funciona plenamente, não vejo isto. }\end{array}$ & $\begin{array}{ll}\text { E1; } & \text { E2; } \\
\text { E5; } & \text { E6; } \\
\text { E8 }\end{array}$ \\
\hline C5 - Uso & $\begin{array}{l}\text { Predominantemente tático. Olham muito a linha de produtos, buscam } \\
\text { entender o consumidor final. Muito focados em inteligência comercial. } \\
\text { Completamente tática. Olhando muito o mix de produtos [...] o } \\
\text { comportamento de compra. }\end{array}$ & $\begin{array}{l}\text { E1; E2; E3; } \\
\text { E6; E7 }\end{array}$ \\
\hline $\begin{array}{l}\text { C6 - } \\
\text { Redes de } \\
\text { inteligênc } \\
\quad \text { ia }\end{array}$ & $\begin{array}{l}\text { Poucas empresas no Brasil são referência nisto, muito poucas. Muitos } \\
\text { profissionais sentem-se donos da informação que possuem e não } \\
\text { compartilham. Nossos empresários (brasileiros) ainda tratam a } \\
\text { informação como um segredo de estado. Há diferenças de } \\
\text { comportamento entre empresas de São Paulo e do Sul. É uma grande } \\
\text { falha, as empresas não têm um sistema de inteligência para coletar as } \\
\text { informações que a equipe tem. Há uma riqueza de informações nas mãos } \\
\text { da equipe de contato com o mercado que as empresas não conseguem } \\
\text { internalizar. }\end{array}$ & $\begin{array}{l}\text { E1; E2; E3; } \\
\text { E5; E6; E7 }\end{array}$ \\
\hline C7 - Estrutura & $\begin{array}{l}\text { Há os robôs de busca, isto é comum. Existe suporte da área de TI, mas } \\
\text { isto não é o mais importante. Há carência de profissionais especializados } \\
\text { no setor. Esta carência de profissionais dificulta a difusão das práticas de } \\
\text { IC no Brasil. Profissionais de outras áreas acabam desenvolvendo a } \\
\text { função. Há acumulo de funções, normalmente com marketing, vendas, } \\
\text { etc. Menos de } 30 \% \text { das organizações brasileiras de grande porte têm } \\
\text { estruturas dedicadas à IC. }\end{array}$ & $\begin{array}{l}\text { E1; E3; E4; } \\
\text { E6; E7; E8; } \\
\text { E13 }\end{array}$ \\
\hline
\end{tabular}




\begin{tabular}{|c|c|c|}
\hline C8 - Localização & $\begin{array}{l}\text { Poucas empresas vinculam a atividade diretamente ao CEO. Na grande } \\
\text { maioria das vezes é uma atribuição vinculada ao marketing ou vendas. } \\
\text { Ligada à área de marketing, a maioria avassaladora. Na maioria das } \\
\text { vezes vinculada a uma diretoria. Vinculada ao marketing, } \\
\text { preponderantemente. Vinculada a um diretor, quase sempre. }\end{array}$ & $\begin{array}{l}\text { E1; E2; E3; } \\
\text { E4; E5; E6; } \\
\text { E7; E8; }\end{array}$ \\
\hline $\begin{array}{l}\text { C9 - } \\
\text { Compartilhamento }\end{array}$ & $\begin{array}{l}\text { Não conheço empresa que incentive formalmente o compartilhamento de } \\
\text { informações. Muito difícil. A cultura do compartilhamento ainda é um } \\
\text { problema. Não tenho conhecimento. É muito raro. }\end{array}$ & $\begin{array}{l}\text { E1; E2; E5; } \\
\text { E6; E7. }\end{array}$ \\
\hline C10 - Comparações & $\begin{array}{l}\text { Grandes empresas dos Estados Unidos e dos países desenvolvidos da } \\
\text { Europa não brincam de IC. As áreas de IC das empresas destes países } \\
\text { estão olhando muito mais a longo prazo. Trata-se de um olhar mais } \\
\text { estratégico. Conheço empresas no exterior que têm profissionais para } \\
\text { monitorar nove idiomas. As empresas de lá monitoram tudo. Estão anos } \\
\text { luz à nossa frente. Elas tomam muita decisão baseados em dados. }\end{array}$ & $\begin{array}{l}\text { E2; E3; E4; } \\
\text { E5; E6; E7; } \\
\text { E11; E14 }\end{array}$ \\
\hline
\end{tabular}

Quadro 6 - Categorias de análise, constatações e fonte Fonte: elaborado pelo autor.

A atividade de IC pode ser considerada como um procedimento recentemente adotado nas organizações brasileiras. Respostas apresentadas pelos entrevistados, consubstanciadas por materiais secundários acessados (Rangel, 2006; Buzzerio \& Marcondes, 2014; Vidigal \& Nassif, 2012; Campelli, Barbejat, Casarotto Filho \& Stefano, 2011; SCIP Brasil, 2016), evidenciam que a IC começou a ser empregada pelas empresas brasileiras na primeira metade da década de 2000. O recente início da aplicação da metodologia pode explicar, ainda que parcialmente, as dificuldades identificadas, nesta pesquisa, no que diz respeito à implementação completa e sistemática do processo de IC nas organizações brasileiras. Em outras palavras, parece que as empresas brasileiras, com algumas exceções, ainda estão aprendendo e ajustando-se aos processos recomendados pelas boas práticas de IC.

Assim, as entrevistas permitiram identificar que há um pequeno e seleto grupo de empresas em operação no Brasil nas quais o processo de IC, contemplando todas suas fases, foi estabelecido e funciona adequadamente. Algumas empresas do setor bancário, de serviços financeiros, de petróleo, da indústria de fármacos e de perfumes, do setor varejista e de serviços de tecnologia estão entre tais empresas, de acordo como os entrevistados. De modo geral, sempre de acordo com a opinião dos entrevistados, o que se constata é a aplicação apenas parcial do processo de IC. Algumas fases desse processo estão em estágio mais avançado, enquanto outras estão em fase inicial ou nem mesmo foram implantadas.

A fase de coleta de informações (Categoria C2) é a que está em estágio mais avançado em termos de aplicação no Brasil. Ferramentas de tecnologia da informação (TI), notadamente às relacionadas à busca e à coleta de informações, estão sendo disseminadas e aplicadas. Há que se destacar, entretanto, que a atividade de busca se caracteriza, de modo preponderante, pela coleta informações de ordem secundária, elemento que pode trazer alguma letargia para o processo competitivo nas organizações. Como referenciado na literatura (Sharp, 2009; Passos, 2005) e reportado por alguns dos entrevistados (E1; E9; E12), quando um evento é divulgado, de tal forma a ser capturado pelas tecnologias de busca, talvez já esteja em estágio avançado, e a possível reação tende a proporcionar benefícios apenas parciais para as organizações.

Apesar da fase de coleta estar funcionando bem, a fase que a antecede, a de planejamento (Categoria C1), evidencia, ressalvado o pequeno e seleto grupo reportado pelos pesquisados, falhas significativas. As respostas apresentadas pelos entrevistados permitem inferir que o mapeamento de quem são os usuários da IC e a respectiva identificação da sua necessidade de informação não são uma realidade consolidada nas empresas brasileiras. Neste sentido, as repostas destacam que, "se for perguntando diretamente para as empresas, elas responderão que sim [que conhecem os usuários e as suas necessidades], mas isto não é uma prática que se verifica" (Entrevistado 3 - E3). Já para E5, "não está claro para a maioria das empresas a sua necessidade de informação"; para E6, "muitas informações ainda seguem um processo de busca ad hoc". Assim, as declarações apresentadas sugerem desvios não recomendados quanto à correta definição do escopo de atuação da área de IC.

O planejamento da atividade de inteligência é uma etapa importante do ciclo de IC, já que é nesta fase que seu escopo será definido (Kahaner, 1997; Ioia, 2014; Passos, 2005). Os recursos destinados à atividade, sua estrutura e o direcionamento de esforços da equipe de inteligência serão mais bem determinados e produzirão melhores resultados se a fase de planejamento for adequadamente executada. Todas as etapas seguintes do ciclo de IC dependem da fase de planejamento (Kahaner, 1997). Um dos maiores problemas que a atividade de IC pode enfrentar é o aumento de seu escopo de atuação, porque uma clara ideia dos objetivos com a atividade não foi definida preliminarmente (Ioia, 2014). 
A fase de análise das informações coletadas (Categoria C3), por sua vez, sofre com a carência de profissionais preparados para atuar na área de IC. Como destacado por E8, "profissionais de outras áreas acabam desempenhando a função, e isto prejudica o desempenho da IC". Para E2, "há [nesta fase] um claro descolamento das etapas anteriores".

Outro elemento que talvez alimente a existência de falhas na fase de análise das informações coletadas pode estar relacionado com a estrutura (Categoria C7) destinada pelas empresas à área de IC. A grande quantidade de informações coletadas e o desempenho concomitante da atividade com outras, notadamente relacionadas às atividades de marketing e vendas, podem inibir o adequado desenvolvimento da etapa de análise das informações coletadas. Como destacado pelos entrevistados, "existe muita coleta e pouca leitura do que é coletado" (E4), "falta tempo para analisar" (E7), "falta método, [...] não há geração de insights" (E8).

A fase de análise das informações recebe destaque na literatura sobre IC como uma das mais relevantes do processo, já que é neste momento que a informação começa a ser transformada em inteligência (Kahaner, 1997; Nicolaos \& Evangellia, 2012; Ioia, 2014). Isso exige habilidade do profissional de IC, pois requer que ele analise a informação, busque padrões e desenvolva cenários baseados no que viu (Kahaner, 1997). A atividade de análise de informações não pode ser desenvolvida por qualquer profissional por requerer capacidade de fazer relações, maturidade de pensamento e experiência em negócios (Sharp, 2009).

$\mathrm{Na}$ fase de disseminação das informações (Categoria C4), identificou-se que a apresentação de sugestões de procedimentos pela equipe de IC ainda não é uma prática comum. Da mesma forma, constatou-se um distanciamento da equipe de IC dos comitês superiores, nos quais decisões de ordem estratégica são tomadas. De fato, não é comum que a equipe de IC participe de reuniões periódicas de planejamento. De acordo com E1, "eu não tenho visto isto não, somente nas empresas muito maduras"; para E6, "não participam, efetivamente não participam". As declarações apresentadas pelos entrevistados também não permitiram identificar o incentivo da alta administração para o compartilhamento de informações entre as equipes nas organizações (Categoria C9). Esta é uma cultura que ainda precisa ser desenvolvida nas organizações brasileiras.

Ressalvado o pequeno e seleto grupo de empresas nas quais o processo de IC funciona adequadamente, a fase do ciclo de IC denominada por Sharp (2009) de ação (Categoria C5), ou uso das informações coletadas (Choo, 2002), também evidencia desvios. Identificou-se o uso predominantemente tático das informações coletadas, destacando-se uma preocupação demasiada com o desempenho de curto prazo nas organizações. Preocupações com o comportamento de compra dentro do ambiente de loja (reação às ações de marketing apresentadas pela empresa), monitoramento do comportamento de preço praticado pelos concorrentes e das ofertas apresentadas pelos demais competidores são exemplos de aplicações identificadas no varejo, por exemplo. Como destacado pelo entrevistado E3, "há uso predominantemente tático". Segundo E2, "olham muito a linha de produtos e os preços praticados pela concorrência", e E1, "muito focados em inteligência comercial". Outros estudos já haviam identificado o uso predominantemente tático das informações coletadas pela área de IC (Vidigal \& Nassif, 2012; SCIP Brasil, 2016).

$\mathrm{O}$ uso tático da IC não é um problema. No entanto, o uso excessivo ou exclusivamente para fins táticos, sim, pode ser considerado como um desvio das finalidades da IC (Wright \& Calof, 2006; Sharp, 2009). Para Wright e Calof (2006), a IC precisa contemplar um escopo maior do que a simples análise de competidores. Para os referidos autores, o objetivo da IC é compreender melhor o ambiente de negócios como um todo, proporcionando às organizações condições mais favoráveis na sua trajetória em busca de vantagem competitiva sustentável. Para Sharp (2009), as empresas costumam reagir tardiamente à mudança e o fazem a diferentes taxas de velocidade. Assim, o foco excessivo no concorrente pode fazer com que a empresa não perceba importantes sinais antecipados de alerta, emitidos por outras fontes, como, por exemplo, os consumidores.

A formação de redes de inteligência (Categoria C6) - ou seja, pessoas externas à empresa detentoras de informação relevante e internas à empresa que, por seu contato direto com o mercado, possuem informação de valor para a organização, elemento importante para a busca e disseminação de informação primária (Jakobiak, 1991; Hannula \& Pirttimäki, 2003; Gomes \& Fraga, 2004; Ioia, 2014), que, como tal, permitiria a identificação antecipada de sinais de mercado - é um procedimento adotado apenas em poucas empresas no Brasil. A riqueza de informação existente nas mãos da equipe que está em contato com o mercado, portanto, não é bem explorada. Não se identificou, nas respostas apresentadas pelos entrevistados, a existência de mecanismos de incentivo e de procedimentos que visassem ao compartilhamento de informações existentes "nas mãos" daqueles profissionais que, pela natureza de suas atividades, encontram-se em constante contato com clientes, concorrentes, redes de lojas e distribuidores, por exemplo. Como destacado pelo entrevistado E6, "é uma grande falha, as empresas não têm um sistema de inteligência para coletar as informações que a equipe tem". Segundo E7, "há uma riqueza de informações nas mãos da equipe de contato com o mercado que as empresas não conseguem internalizar". $\mathrm{O}$ estudo desenvolvido por Rangel (2006) já havia identificado falhas na formação de redes de inteligência por parte das empresas brasileiras.

A estrutura destinada à área (Categoria C7) de IC e a sua localização no organograma (Categoria C8) revelam a importância que lhe é atribuída (Laackman, 
Saban \& Lanasa, 2000; Ioia, 2014). Os resultados apurados neste estudo sugerem que, embora haja suporte de tecnologia da informação, como a aplicação de softwares de busca de informação, há, por parte das empresas brasileiras, pouca ênfase na alocação de equipes preparadas e exclusivas para o desempenho da atividade. Esse resultado está coerente com o identificado em outros estudos (Vidigal \& Nassif, 2012; Rodrigues, Sierra \& Rechziegel, 2014; SCIP Brasil, 2016). Como relatado por E6, "há acúmulo de funções, normalmente com marketing e vendas". Além do acúmulo de funções, destacou-se a questão da existência de poucos profissionais, no mercado, adequadamente capacitados para o desempenho da função (E8). A localização no organograma, por sua vez, raramente foi citada como ligada diretamente ao $C E O$. Na maioria das vezes trata-se de uma atribuição vinculada à diretoria de marketing ou de vendas.

Estruturas de IC vinculadas diretamente ao $C E O$ são procedimentos recomendados pela literatura analisada (Laackamn et al., 2000; Ioia, 2014). O problema de vincular-se a atividade a uma diretoria específica implica, muitas vezes, dar mais atenção às questões relacionadas àquela diretoria do que às necessidades de IC demandadas pela organização como um todo.

Afirmar que uma empresa, qualquer que seja o seu porte, não adote práticas de IC é semelhante a afirmar que as empresas, de modo geral, não possuem controle sobre seu fluxo de caixa. Assim como toda empresa possui algum nível de controle sobre seu fluxo de caixa, alguma prática de IC é adotada por qualquer empresa, mesmo que de forma ad hoc, incompleta e não processual. Entretanto, quando um olhar mais refinado é aplicado sobre os procedimentos desenvolvidos pelas organizações, desvios e inconsistências são identificados.

O procedimento de análise aplicado no presente estudo identificou, mediante a consulta a especialistas sobre o tema e busca complementar em outros estudos já desenvolvidos sobre o assunto, desvios e inconsistências de procedimentos em quase todas as etapas do ciclo de IC. Tal fato revela que as organizações brasileiras, ressalvados o pequeno e seleto grupo de empresas destacado pelos entrevistados, ainda têm uma longa trajetória a percorrer em termos da adequada implementação dos processos relacionados às etapas do ciclo de IC. Quando se realizam comparações com empresas dos Estados Unidos, ou de países desenvolvidos da Europa (Categoria C10), constata-se que elas "estão anos luz à nossa frente" (E3), pois trata-se de empresas que "tomam muita decisão baseadas em dados fornecidos pela área de IC” (E2).

\section{CONSIDERAÇÕES FINAIS}

Dois objetivos nortearam o presente trabalho. $\mathrm{O}$ primeiro foi estudar os conceitos de inteligência competitiva e capacidades dinâmicas, buscando identificar se as etapas do ciclo de inteligência competitiva podem se constituir em elementos mobilizadores de capacidades dinâmicas nas organizações. O segundo, envolveu identificar como se encontra o processo de inteligência competitiva nas organizações brasileiras de médio e grande porte, tendo como base a opinião de especialistas sobre o tema.

Quanto ao primeiro objetivo, sugere-se que se CDs requerem identificar e avaliar oportunidades (sensing), mobilizar recursos para beneficiar-se da oportunidade (seizing) e trabalhar para a continuada renovação do negócio (transforming) (Teece, 2012), então as etapas do ciclo de IC podem ser consideradas como mecanismos mobilizadores de CDs. Seus fundamentos residem na busca de informações internas e externas sobre competidores, clientes, fornecedores, tecnologias e outros negócios em potencial, tendo como objetivo proporcionar alertas antecipados sobre eventos que possam ter impacto significativo sobre o desempenho e o futuro do negócio (Calof \& Wright, 2008).

Considera-se que as etapas do ciclo de inteligência contribuem para a mobilização de capacidades dinâmicas nas organizações, tendo em vista que: i) proporcionam aos gestores a oportunidade de pensar sobre o ambiente de negócios e discutir sobre as informações necessárias para ampliar o seu conhecimento sobre o mesmo (fase de planejamento); ii) incentivam a curiosidade organizacional (fase de coleta); iii) proporcionam alertas antecipados e a descoberta de padrões, de relacionamentos, favorecendo a discussão de cenários competitivos (fase de análise); iv) oferecem inteligência aos gestores e dão a oportunidade para a criatividade entrar em ação (fase de disseminação) e v) contribuem para a renovação do negócio (fase de uso dos produtos da IC).

Infere-se, assim, que as etapas do ciclo de IC constituem-se em elementos que contribuem para a mobilização de CDs nas organizações, pois incentivam a busca de informações, a discussão de diferentes opiniões e visões sobre oportunidades e ameaças, favorecem a identificação de padrões e o desenvolvimento de cenários competitivos. Oferecem, também, o conhecimento necessário (inteligência) para a definição de cursos de ação mais embasados.

No que diz respeito ao segundo objetivo, embasado em recomendações identificadas por ocasião do desenvolvimento do referencial teórico (Wright \& Calof, 2006; Reinmoeller \& Ansari, 2016), preferiu-se estabelecer como fonte primária de informações a opinião de especialistas em IC. Entendeu-se que a obtenção de informações diretamente de executivos atuantes nas referidas áreas das empresas poderia influenciar nas respostas, tendo em vista o compromisso de tais profissionais com o adequado desenvolvimento da atividade nas respectivas empresas. Também houve a coleta de material secundário, tendo como finalidade realizar, sempre que possível, a triangulação de informações. Os referidos 
materiais foram compostos por outros estudos, como pesquisas realizadas por organizações representativas de classe, artigos publicados por outros pesquisadores, dissertações de mestrado e tese de doutorado.

Os resultados da pesquisa sugerem que a IC, ressalvado um pequeno e seleto grupo de empresas reportado pelos entrevistados, é a uma atividade recentemente implantada nas empresas brasileiras e que ainda se encontra em estágio inicial de desenvolvimento no Brasil.

De fato, foram observados problemas em quase todas as etapas do ciclo de IC. A fase identificada como a mais desenvolvida foi a de coleta de dados. As demais fases, como a de identificação da necessidade e dos reais usuários das informações, a realização de análise qualificada e cuidadosa, a disseminação e o uso de informações geradas pela área de IC sugerem a existência de desvios significativos que precisam ser ajustados pelas empresas. A formação de redes de inteligência, a construção de uma cultura de compartilhamento de informações, bem como a adequada localização da área no organograma organizacional, visando ao pleno desenvolvimento e aproveitamento das suas potencialidades, por sua vez, também foram identificados como aspectos merecedores de atenção.

A constatação de que a IC tem uso predominantemente tático evidencia preocupação demasiada com o desempenho de curto prazo nas organizações. O escopo da atividade, para efetivamente contribuir para renovação e a sustentabilidade do negócio no longo prazo, precisa ser ampliado. O objetivo da IC é possibilitar a melhor compreensão do ambiente de negócios como um todo, proporcionando às organizações condições mais favoráveis na sua trajetória para a busca da vantagem competitiva.

No presente estudo inferiu-se que as etapas do ciclo de IC contribuem para o desenvolvimento de CDs nas organizações. Foram apresentados argumentos neste sentido, mas não foram apresentadas evidencias empíricas sustentado tal fato. Esta limitação oferece oportunidade para o desenvolvimento de estudos futuros, tendo como objetivo testar a referida inferência. Outras limitações do presente estudo envolvem questões tradicionalmente relatadas em estudos de natureza qualitativa. As constatações apresentadas, apesar da convergência de opiniões observada durante os processos de coleta e análise, refletem a opinião dos especialistas entrevistados, impedindo a realização de generalizações.

\section{REFERÊNCIAS}

Alsos, G. A., Borch, O. J., Ljunggren, E. \& Madsen, E. L. (2008). Dynamic Capabilities: Conceptualization and Operationalization. Artigo apresentado The Academy of Management Conference 2008; Anaheim, USA.
Andreeva, T. \& Chaika, V. (2006). Dynamic Capabilities: What They Need to be Dynamic? [Working Paper, 10 (E)] St. Petersburg State University; São Petersburgo.

Argote, L. Ren, Y. (2012). Transactive Memory Systems: A Microfoundation of Dynamic Capabilities. Journal of Management Studies. p. 18 .

Ambrosini, V. \& Bowman, C. (2009). What Are Dynamic Capabilities and Are They a Useful Construct in Strange Management? Internatonl Journal of Management Reviews, v. 11, n. 1, p. 2949.

Bardin, L. (2009). Análise de conteúdo (L. A. Reto \& A. Pinheiro, Trad.) Lisboa. Edições 70.

Barney, J. B. (1991). Firm resources and sustained competitive advantage. Journal of Management, 17 (1), 99-120.

Buzzerio, F. G. \& Marcondes, R. C. (2014). A Inteligência Competitiva na Perspectiva de ser uma Fonte de Vantagem Competitiva e Suas Contribuições Estratégicas. Revista de Ciências da Administração, v. 16, n. 40, p. 235-249.

Calof, J. \& Wright, S. (2008). Competitive Intelligence: A Practitioner, Academic and Interdisciplinary Perspective. European Journal of Marketing, v. 42, n. 7/8, p. 717-730.

Campelli, M. G. R., Barbejat, M. E., Casarotto Filho, N. \& Stefano, N. M. (2011). Perspectivas da Inteligência Competitiva no Brasil. Artigo Apresentado no XXXIX Congresso Brasileiro de Educação em Engenharias - COBENGE 2011; Blumenau, SC.

Castro, L. B de. (2005). Privatização, Abertura e Desindexação: A Primeira Metade dos Anos 90. In Economia Brasileira Contemporânea. Giambiagi, Fabio; Villela, André. (Orgs). Rio de Janeiro: Elsevier.

Choo, C. W. (2002). Information Management for The Intelligent Organization. American Society for Information Science and Technology. Medford, New Jersey.

Collis, D. J. (1994). Research Note: How Valuable are Organizational Capabilities? Strategic Management Journal, 15 (suppl.), p. 143-152.

Colvin, G. (2015). The 21st Century Corporation: Every Aspect of Your Business is About to Change. Fortune, November, p. 39-47. 
Danneels, E. (2010). Trying to become a different type of company: Dynamic capability at Smith Corona. Strategic Management Journal, 32, 1-31.

Dishman, P.L. \& Calof, J. L. (2008). Competitive Intelligence: a Multiphasic Precedent to Marketing Strategy. European Journal of Marketing, 42, $\mathrm{N}^{\mathrm{o}}$ 7/8, 766-785.

Drnevich, P. L. \& Kriauciunas, A. P. (2011). Clarifying The Conditions and Limits of the Contributions of Ordinary and Dynamic Capabilities to Relative Firm Performance. Strategic Management Journal, v. 32. P. 254-279.

Eisenhardt, K. \& Martin, J. (2000) Dynamic capabilities: What are they? Strategic Management Journal, 21, 1105-1121.

Franco, Maria Laura P. B. (2007). Análise de conteúdo. Brasília, DF. Líber Livro.

Fuld, L. M. (2007). Inteligência Competitiva: Como se Manter à Frente dos Movimentos da Concorrência e do Mercado. Rio de Janeiro. Elsevier.

Gilad, B. (1989). The Role of Organized Competitive Intelligence in Corporate Strategy. Columbia Journal of World Business. V. 24, n. 4, p. 29-36.

Gomes, E. \& Braga, F. (2004). Inteligência Competitiva: Como Transformar Informação em um Negócio Lucrativo. São Paulo: Elsevier.

Guerra, R. M. A., Tondolo, V. A. G. \& Camargo, M. E. (2016). O que (ainda) Podemos Aprender sobre Capacidades Dinâmicas. Revista Ibero-Americana de Estratégia-RIAE, v. 15. N. 1, p. 44-64.

Hannula, M. \& Pirttimäki, V. (2003). Business Intelligence: Empirical Study on the top 50 Finnish Companies. The Journal of American Academy of Business, v.2, n.2, p.593-599.

Harreld, J. B., O’Reilly III \& Tushman, M. L. (2007). Dynamic Capabilities at IBM: Driving Strategy into Action. California Management Review, v. 49, n. 4, p. 21-43.

Helfat, C. E., Finkelstein, S., Mitchell, W., Peteraf, M. A., Singh, H., Teece, D. J. \& Winter, S. G. (2007). Dynamic capabilities: understanding strategic change in organizations. Oxford: Blackwell Publishing.

Helfat, C. E. \& Peteraf, M. A. (2009). Understanding dynamic capabilities: progress along a developmental path. Strategic Organization, 7 (1), 91-102.
Helfat, C. E. \& Peteraf, M. (2003). The Dynamic Resource-Based View: Capability Lifecycles. Strategic Management Journal, v. 24, p. 997-1010.

Heneman, H. G. (1974). Comparisons of Self and Superior Ratings. Journal of Applied Psychology, v. 59, n. 5, p. 638-642.

Ioia, M. (2014). The New Rules of Competitive Intelligence. Middletown, Delaware: Xlibris.

Jakobiak, F. (1991). Pratique de la Veille Technologique. Paris. Ed. d'Organisation.

Jin, T. \& Bouthillier, F. (2013). What Do Competitive Intelligence Professonals Do? A Pilot Study. Working Paper. Disponível em 12/10/2015 em http://www.cais-

acsi.ca/ojs/index.php/cais/article/view/697/454.

Kahaner, L. (1997). Competitive Intelligence: How to Gather, Analyze, and Use Information to Move Your Business to the Top. New York: Touchstone.

Laackman, C., Saban, K. \& Lanasa, J. (2000). Organizing the Competitive Intelligence Function Benchmark. Competitive Intelligence Review. V. 11, n. 1, p. 17-27.

Leavitt, P., Prescott, J., Lemons, D. \& Hasanali, F. (2004). Competitive Intelligence: A Guide for Your Journey to Best Practice Processes. Texas. American Productivity \& Quality Centre.

Magretta, J. (2012). Understanding Michael Porter: the Essential Guide to Competition and Strategy. Boston, Massachusetts: Harvard Business School Publishing.

Marcus, A. A. \& Anderson, M. H. (2006). A General Dynamic Capability: Does It Propagate Business and Social Competencies in the Retail Food Industry? Journal Of Management Studies, v. 43, n. 1, p. 19-46.

McKelvie, A. \& Davidsson, P. (2009). From Resource Base to Dynamic Capabilities: An Investigation of New Firms. British Journal of Management, 20 (Suppl.), P. $63-80$.

Meirelles, D. S. \& Camargo, A. A. B. (2014). Capacidades Dinâmicas: O Que São e Como Identificá-las? Revista de Administração Contemporânea - RAC, v. 18, Ed. Especial, p. 4164.

Miller, J. P. (2002). O Processo de Inteligência: como Funciona, Seus Benefícios e Sua Situação Atual. In Miller, J. P. O Milênio da Inteligência Competitiva. Porto Alegre. Bookman, p. 31-44. 
Molina, V. B., Bustinza, O. F. \& Gutiérrez-Gutiérrez, L. J. (2013). Explaining The Causes and Effects of Dynamic Capabilities Generation: A MultipleIndicator Multiple-Cause Modeling Approach. British Journal of Management, v. 24, n. 4, p. 571591.

Montealegre, R. (2012). A Process Model of Capability Development: Lessons from Electronic Commerce Strategy at Bolsa de Valores de Guayaquil. Organization Science, v. 13, n. 5, p.514-531.

Nikolaos, T. \& Evangelia, F. (2012). Competitive Intelligence: Concept, Context and Case os its Application. Science Journal of Business Management, v. 2, p. 1-15.

Passos, A. (2005). Inteligência Competitiva: Como Fazer IC Acontecer na Sua Empresa. São Paulo: LCTE Editora.

Pirtilla, A. (1998). Organizing Competitive Intelligence Activities in a Corporate Organization. Aslib Proceedings, n. 50, v. 4, p. 79-84.

Porter, M. (1980). Competitive Strategy. NY: Free Press.

Porter, M. (2008). The Five Competitive Forces That Shape Strategy. Harvard Business Review, January: 78-93.

Porter, M. \& Heppelmann, J. (2014). How Smart, Connected Products Are Transforming Competition. Harvard Business Review, November: 65-88.

Porter, M. \& Heppelmann, J. (2015). How Smart, Connected Products are Transforming Companies. Harvard Business Review, October: 64-83.

Prescott, J. E. (1999). The Evolution of Competitive Intelligence: Designing a Process for Action. Journal of The Association of Proposal Management Professionals, Spring, p. 37-52.

Qiu, T. (2008). Scanning for Competitive Intelligence: a Managerial Perspective. European Journal of Marketing: v. 42, n. 7/8, p. 814-835.

Rangel, L. C. (2006). A Sofisticação da Atividade de Inteligência Competitiva no Brasil: um Estudo Exploratório. Dissertação de Mestrado. Universidade Federal do Rio de Janeiro, Instituto Coppead de Administração, Rio de Janeiro, Brasil.

Reinmoeller, P. \& Ansari, S. (2016). The Persistence of a Stigmatised Practice: A Study of Competitive Intelligence. British Journal of Management: vol. 27, n. 1, p. 116-142.
Rifkin, J. (2014). The Zero Marginal Cost Society: the Internet of Things, the Collaborative Commons, and the Eclipse of Capitalism. New York: Palgrave Macmillar.

Rodrigues, L. C., Sierra, J. C. V. \& Rechziegel, W. (2014). Maturidade Organizacional em Inteligência Competitiva - O Caso de uma Instituição Financeira Brasileira. Revista de Ciências da Administração: v. 16, n. 38, p. 126-139.

Scip Brasil. (2016). Pesquisa Strategic and Competitive Intelligence Professionals / Brasil 2015 - 2016.

Sharp, S. (2009). Competitive Intelligence Advantage: How to Minimize Risk, AVoid Surprises, and Grow Your Business in a Changig World. Hoboken, New Jersey: John Wiley \& Soons, Inc.

Teece, D. j., Pisano, G. \& Shuen, A. (1997). Dynamic Capabilities and Strategic Management. Strategic Management Journal. Vol. 18, nº 7, p. 509-533.

Teece, D. J. (2007). Explicating Dynamic Capabilities: the Nature and Microfoundations of (sustainable) Enterprise Performance. Strategic Management Journal, v. 28, n. 7, p. 1319-1350.

Teece, D. J. (2012). Dynamic Capabilities: Routines versus Entrepreneurial Action. Journal of Management Studies, v. 49, n. 8, p. 1395-1401.

Tondolo, V. A. G., Bitencourt, C. C. (2014). Compreendendo as Capacidades Dinâmicas a Partir de Seus Antecedentes, Processos e Resultados. Brazilian Business Review, v. 11, n. 5, p. 124-147.

Ullrich, D. R., Oliveira, J. S., Basso, K. \& Visentini, M. S. (2012). Reflexões Teóricas sobre Confiabilidade e Validade em Pesquisas Qualitativas: em Direção à Reflexividade Analítica. Análise, v. 23, n. 1, p. 19-30.

Vidigal, F. \& Nassif, M. E. (2012). Inteligência Competitiva: Metodologias Aplicadas em Empresas Brasileiras. Informação, v. 17, n. 1, p. 93-119.

Wang, C. L. \& Ahmed, P. K. (2007). Dynamic Capabilities: A Review and Research Agenda. International Journal of Management Reviews, v. 9 , n. 1, p. 31-51.

Wernerfelt, B. A resource-based view of the firm. (1984). Strategic Management Journal, v.5 n. 2, 157-170.

Winter, S. G. (2003). Understanding Dynamic Capabilities. Strategic Management Journal, v. 24 (10), p. 991-995. 
Wright, S. \& Calof, J. L. (2006). The Quest for Competitive, Business and Marketing Intelligence: A Country Comparision of Current Practices. European Journal of Marketing. V. 40, n. 5/6, p. 453-465.

Zahra, S. A., Sapienza, H. J. \& Davidsson, P. (2006). Entrepreneurship and Dynamic Capabilities: a
Review, Model and Research Agenda. Journal of Management Studies, v. 43, n. 4, p. 017-955.

Zollo, M.; Winter, S. G. Deliberate Learning and the Evolution of Dynamic Capabilities. Organization Science, v. 13, n. 3, p. 339-351, 2002. 